\title{
The Effects of Upper Body Muscle Strength Training on Anthropometric Measurements and Cardiopulmonary Function in Obese Women
}

J. Phys. Ther. Sci.

22: $161-166,2010$

\author{
YILDIZ YAPRAK ${ }^{1)}$, BEHICE DURGUN ${ }^{2)}$, SADİ KURDAK ${ }^{3)}$ \\ 1) Physical Education and Sports Department, Mustafa Kemal University: Hatay, Turkey. \\ TEL: +90 326-2275888 \\ 2) Department of Anatomy, Faculty of Medicine, Çukurova University, Turkey \\ ${ }^{3)}$ Department of Physiology, Faculty of Medicine, Çukurova University, Turkey
}

\begin{abstract}
Purpose] The purpose of this study was to investigate the effects of upper body muscle strength training on anthropometric measurements and cardiopulmonary function in healthy obese women. [Subjects] Sixty-three obese women (age: $37.96 \pm 2.25$ years, height: $158.99 \pm 5.76 \mathrm{~cm}$, body weight: 83.65 $\pm 11.24 \mathrm{~kg}$, body mass index: $33.11 \pm 4.31 \mathrm{~kg} / \mathrm{m}^{2}$ ) volunteered to participate in this study. [Methods] The participants were divided into 3 groups. The aerobic (A) group performed diet plus aerobic exercise on a bicycle ergometer for 45-60 min, 3 times a week for 8 weeks, while the aerobic-strength (AS) group performed strength training with the barbell and their body weight plus diet and aerobic exercise. C group was the control. The spirometer test, gas analysis and anthropometric measurements were performed for all three groups before and after training. SPSS 11.0 statistical software was used to perform all the analysis. Comparisons were made using one-way ANOVA. [Results] The present findings show that, there were significant differences between pre- and post-training measures of anthropometric parameters and cardiopulmonary function in the study groups. After $8 \mathrm{wk}$ of training, forced vital capacity (FVC) and maximum voluntary ventilation (MVV) of the AS group showed a significant increase $(16.19 \%$ and $13.77 \%$ ). Furthermore, $\mathrm{VO}_{2}$ max parameters of the $\mathrm{A}$ and AS groups showed a significant increase (8.48$6.15 \%$ ). [Conclusions] Diet and aerobic training in obese women significantly improved their morphological structure and aerobic capacity. However, diet plus aerobic and strength training significantly increased muscle strength of the upper body and accessory respiratory muscles. Therefore pulmonary functions parameters such as FVC and MVV values increased.
\end{abstract}

Key words: Anthropometry, Obesity, Upper body muscle training.

(This article was submitted Oct. 22, 2009, and was accepted Dec. 28, 2009)

\section{INTRODUCTION}

Obesity is a serious health problem that reduces life expectancy and threatens quality of life ${ }^{1)}$. Obesity reflects the accumulation of triglycerides in fat deposits, leading to adipocyte hypertrophy and hyperplasia ${ }^{2)}$. Anthropometric indexes such as the body mass index (BMI), waist/hip ratio $(\mathrm{W} / \mathrm{H})$, waist circumference, and waist/height ratio (WHTR) remain the most commonly used tools for assessing body composition. Genetic factors and hormonal diseases such as hypothyroidism, Cushing's syndrome and certain drugs such as steroids and some antidepressant and psychological 
factors may cause excessive weigth gain. These factors are the main causes of obesity, an energy imbalance in the body, in which for every 3,500 kcal of excess energy accumulated, $450 \mathrm{~g}$ of fat is stored in the body ${ }^{1,3}$.

Obesity has an impact on virtually all organ systems, including the cardiovascular, respiratory (obstructive sleep apnea, hypoventilation), metabolic and osteoarticular systems ${ }^{2)}$. The respiratory muscles in obese individuals have been characterized as inefficient, and their endurance has also been found to be low. This inefficiency results from reduced chest wall compliance, smaller pulmonary volumes, greater metabolic demand on the respiratory musculature and increased work required for breathing ${ }^{4}$.

Many studies have reported an inverse relation between obesity or fat distribution and respiratory function. Clinical studies have reported that the W/ $\mathrm{H}$ ratio, as a measure of abdominal obesity is associated with poor respiratory function in both mildly and morbidly obese subjects ${ }^{5)}$. Sahebjami et al. found that MVV, which may be affected by reduced respiratory muscle strength, was low in obese patients ${ }^{6}$. Furthermore, morbidly obese individuals have poorer exercise capacity and may also have poorer pulmonary gas exchange than their nonobese counterparts because of the added energy needed to move fat mass ${ }^{7}$. There are some reports about improvement of the respiratory muscles function by training of other skeletal muscles. Ries et al. (1997) reported that the strength of shoulder girdle muscles was increased by training of the upper extremity muscles in chronic obstructive lung disease patients ${ }^{8)}$. Furthermore Al-Bilbeisi et al. and DePalo et al. reported that non-respiratory maneuvers such as biceps curls and sit-ups could improve inspiratory muscle strength, expiratory muscle strength, and diaphragm strength ${ }^{9,10}$.

The purpose of this study was to compare the effects of energy restriction plus aerobic training and upper body muscles strength training, such as weight lifting, and abdominal crunch, on anthropometric measurements and cardiopulmonary functions in healthy obese women.

\section{SUBJECTS AND METHODS}

Subjects: Sixty-three healthy obese women (age: $37.96 \pm 2.25$ years, height: $158.99 \pm 5.76 \mathrm{~cm}$, body weight (BW): $83.65 \pm 11.24 \mathrm{~kg}$, body mass index
(BMI): $\left.33.11 \pm 4.31 \mathrm{~kg} / \mathrm{m}^{2}\right)$.

Material: Ergospirometer (Quark PFT, Cosmed, Italy), skin fold caliper (Harpenden, England), anthropometric set (Harpenden, England), tape measure, barbell, bicycle ergometer, and electronic scale.

Measurements: Anthropometric Measurement: W/ $\mathrm{H}$ Ratio: The circumference of the waist was measured between the iliac crest and the last costa with a tape measure. The circumference of the hip was measured as the greatest circumference of the gluteus maximus muscle in the standing position. Body fat measurement: Skin fold thickness was measured in three regions using standard methods for body fat mass. The body density was calculated using the three measurements; then the body fat was estimated using the formula of Jackson et al. for fat mass.

Body density $=1.099421-0.0009929(\Sigma 3 f)+0.0000023(\Sigma 3 f)^{2}$

Fat $\%=(4.95 /$ Body density $)-4.5) \times 100$ -0.0001392 (age)

$(\Sigma 3 \mathrm{f}=\text { triceps } \mathrm{SF}+\text { thigh } \mathrm{SF}+\operatorname{suprailiac} \mathrm{SF})^{3,11,12)}$.

Pulmonary Function Measurements: Each subject performed two acceptable FVC, and MVV maneuvers according to standard methods. The FVC test was performed with the subjects in the standing position while the MVV test was performed with the subjects in the sitting position.

Maximal oxygen uptake $\left(\mathrm{VO}_{2} \max \right)$ : An ergospirometric test was performed on a treadmill using the Bruce protocol. Calibrations were performed prior to each test. Gas analysis was performed automatically every 3-4 seconds while the subjects walked or ran on the treadmill. The test was ended when subjects gave up through exhaustion, $\mathrm{R}$ was greater than 1.10 , or there was no further increase in maximal oxygen uptake ${ }^{1)}$.

The spirometer test, gas analysis and anthropometric measurements were made before and after 8 weeks.

Training: The participants were divided into three groups at random:

A group observed a diet and performed aerobic exercise at a constant load on a bicycle ergometer for 45-60 min, 3 times a week for 8 weeks. Exercise intensity was prescribed according to the Karvonen formula (Target exercise heart rate $\left.(\mathrm{HR})=\left(\mathrm{HR}_{\max }-\mathrm{HR}_{\text {rest }}\right) \times 0.6+\mathrm{HR}_{\text {rest }} \pm 5\right)$ 
Table 1. Baseline Characteristics of Obese Women $(n=63)$

\begin{tabular}{|c|c|c|c|c|c|c|c|c|c|}
\hline $\begin{array}{c}\text { Groups } \\
\mathrm{n}\end{array}$ & \multicolumn{3}{|c|}{$\begin{array}{c}\text { Control }(\mathrm{C}) \\
22\end{array}$} & \multicolumn{3}{|c|}{$\begin{array}{c}\text { Aerobic (A) } \\
21\end{array}$} & \multicolumn{3}{|c|}{$\begin{array}{l}\text { Aerobic-Strength (AS) } \\
20\end{array}$} \\
\hline Age (Yr) & \multicolumn{3}{|c|}{$38.36 \pm 2.47$} & \multicolumn{3}{|c|}{$37.57 \pm 2.11$} & \multicolumn{3}{|c|}{$37.95 \pm 2.18$} \\
\hline \multirow[t]{2}{*}{ Height $(\mathrm{cm})$} & & $57.72 \pm 5.49$ & & & $159.52 \pm 5.3$ & & & $59.82 \pm 6.45$ & \\
\hline & Before & After & $\begin{array}{c}\% \\
\text { change }\end{array}$ & Before & After & $\begin{array}{c}\% \\
\text { change }\end{array}$ & Before & After & $\begin{array}{c}\% \\
\text { change }\end{array}$ \\
\hline $\mathrm{HR}(\mathrm{bpm})$ & $79.72 \pm 7.92$ & $80.00 \pm 5.76$ & $0.35+$ & $81.57 \pm 9.69$ & $77.66 \pm 6.23$ & $4.79-$ & $79.47 \pm 7.44$ & $76.57 \pm 7.89$ & 3.64 \\
\hline Blood press. (systolic) (mmHg) & $116.6 \pm 16.2$ & $116.5 \pm 13.2$ & - & $115.2 \pm 13.8$ & $110.1 \pm 13$ & $4.41-$ & $122.5 \pm 19.2$ & $118.7 \pm 17.7$ & $3.10-$ \\
\hline Blood press. (diastolic) (mmHg) & $77.40 \pm 10.9$ & $78.40 \pm 7.73$ & $1.29+$ & $75.85 \pm 7.28$ & $77.19 \pm 8.45$ & $1.76+$ & $82.38 \pm 9.73$ & $81.80 \pm 13.8$ & $30.70-$ \\
\hline
\end{tabular}

Table 2. Anthropometric Parameters of Obese Women $(n=63)$

\begin{tabular}{|c|c|c|c|c|c|c|c|c|c|}
\hline \multirow[t]{2}{*}{$\begin{array}{c}\text { Groups } \\
\mathrm{n}\end{array}$} & \multicolumn{3}{|c|}{$\begin{array}{c}\text { Control }(\mathrm{C}) \\
22\end{array}$} & \multicolumn{3}{|c|}{$\begin{array}{c}\text { Aerobic (A) } \\
21\end{array}$} & \multicolumn{3}{|c|}{$\begin{array}{c}\text { Aerobic-Strength (AS) } \\
20\end{array}$} \\
\hline & Bef & After & $\begin{array}{c}\% \\
\text { change }\end{array}$ & e & After & $\begin{array}{c}\% \\
\text { change }\end{array}$ & Before & After & $\begin{array}{c}\% \\
\text { change }\end{array}$ \\
\hline BW ( & 7 & $80.22 \pm 11.7$ & $0.48-$ & 27 & $7742+$ & 7.53 & $86.92 \pm 14$ & 30.19 & $7.13-$ \\
\hline BMI $\left(\mathrm{kg} / \mathrm{m}^{2}\right)$ & 19 & $32.37 \pm$ & 0 . & 329 & $3055+$ & & 4.55 & 32 & \\
\hline Waist c & & $92.04 \pm 10.44$ & - & & $85.47 \pm$ & & & 89.53 & \\
\hline Hip cir & 114.2 & $113.77 \pm$ & $0.13-$ & 116 & $111.59 \pm$ & $4.48-$ & .5 & 112.1 & $4.57-$ \\
\hline W/H Ratio & 5 & 5 & - & & $0.77 \pm$ & - & $0.79 \pm$ & 0.79 & - \\
\hline Suprailiac SF (mm) & $31.13 \pm 7.29$ & $30.70 \pm 7.74$ & $1.38-$ & $32.77 \pm 5.48$ & $27.60 \pm 6.48^{*}$ & 14 & $32.02 \pm 8.31$ & $28.75 \pm 7.85$ & $10.21-$ \\
\hline Triceps SF (mm) & $33.65 \pm 5.98$ & $33.48 \pm 6.11$ & - & $37.16 \pm 3.58$ & $33.26 \pm 4.78^{*}$ & $11.40-$ & $34.81 \pm 6.44$ & $30.84 \pm 7.01$ & $10.66-$ \\
\hline Thigh SF (mm) & $43.24 \pm 3.46$ & $43.12 \pm 3.38$ & - & $44.04 \pm 1.53$ & $42.51 \pm 1.75$ & $3.47-$ & $42.94 \pm 3.45$ & $41.18 \pm 4.12 *$ & $4.09-$ \\
\hline FM (\%) & $38.35 \pm 3.77$ & $38.02 \pm 4.02$ & $0.89-$ & $39.61 \pm 2.51$ & $37.02 \pm 2.76^{*}$ & $6.53-$ & $38.50 \pm 3.89$ & $36.50 \pm 4.25$ & $5.19-$ \\
\hline
\end{tabular}

$(* \mathrm{p}<0.05$ compared to the Control).

First 4 weeks; warm up 10 min + stretching + aerobic exercise on bicycle $45 \mathrm{~min}+$ cool down 5 min. In the last 4 weeks; the aerobic exercise time was increased by $15 \mathrm{~min}$.

$A S$ group observed a diet and performed aerobic exercise plus strength training. The AS group performed the following strength exercises; bench press (incline bench), fly (lying), fly (standing), and bent-arm barbell pullover ${ }^{13)}$ in 2 sets of 10 repeats in the first 4 weeks and 3 sets of 10 repeats in the last 4 weeks; plus abdominal crunch, 3 sets of maximal $50 \%$ in the first 4 weeks and 4 sets of maximal $50 \%$ in the last 4 weeks.

Weight of barbells were adjusted to $50 \%$ of maximal weight for each exercise.

$C$ group performed no exercise and observed no dietary restriction during the same time. Only anthropometric and cardiopulmonary tests were measured before and after 8 weeks.

The A and AS groups observed a low calorie diet $(1,200 \mathrm{cal})$ during the 8 weeks. We took care that none of the subjects suffered from diseases of the airway or fatigue during the study. All subjects gave their informed consent.

Statistical Analysis: SPSS 11.0 statistical software was used to perform all the analysis. Each parameter was calculated as mean \pm standard deviation (SD). Differences among the three groups were tested using one-way ANOVA (Scheffe test); $p<0.05$ was considered significant.

\section{RESULTS}

The mean, SD and changes of HR, systolic and diastolic blood pressure are presented in Table 1. There were no significant differences in these parameters between pre- and post-training in the 3 groups.

The anthropometric measurements of the obese women are presented in Table 2. There were significant decrease in all anthropometric values except the $\mathrm{W} / \mathrm{H}$ ratio in the A and AS groups. Oneway ANOVA showed significant decreases only for hip circumference and thigh SF parameters in the AS group, and significant decrease for the other 
Table 3. Spirometric Parameters of Obese Women $(n=63)$

\begin{tabular}{|c|c|c|c|c|c|c|c|c|c|}
\hline \multirow[t]{2}{*}{$\begin{array}{c}\text { Groups } \\
\mathrm{n}\end{array}$} & \multicolumn{3}{|c|}{$\begin{array}{c}\text { Control }(\mathrm{C}) \\
22\end{array}$} & \multicolumn{3}{|c|}{$\begin{array}{l}\text { Aerobic (A) } \\
21\end{array}$} & \multicolumn{3}{|c|}{$\begin{array}{c}\text { Aerobic-Strength (AS) } \\
20\end{array}$} \\
\hline & Before & After & $\begin{array}{c}\% \\
\text { change }\end{array}$ & Before & After & $\begin{array}{c}\% \\
\text { change }\end{array}$ & Before & After & $\begin{array}{c}\% \\
\text { change }\end{array}$ \\
\hline FVC (1t) & $2.53 \pm 0.48$ & $2.64 \pm 0.38$ & $4.34+$ & $2.66 \pm 0.59$ & $2.95 \pm 0.62$ & $10.90+$ & $2.59 \pm 0.51$ & $3.03 \pm 0.47 * *$ & $16.98+$ \\
\hline FEV1 (lt) & $2.45 \pm 0.53$ & $2.52 \pm 0.39$ & $2.85+$ & $2.45 \pm 0.54$ & $2.69 \pm 0.56$ & $9.79+$ & $2.47 \pm 0.46$ & $2.74 \pm 0.45$ & $10.93+$ \\
\hline FEV1/FVC (lt) & $96.065 \pm 6.74$ & $95.37 \pm 5.91$ & $0.71+$ & $94.19 \pm 6.16$ & $94.85 \pm 6.43$ & $0.70+$ & $91.5 \pm 14.2$ & $96.2 \pm 2.96$ & $5.13+$ \\
\hline PEF (lt/s) & $5.66 \pm 1.44$ & $5.81 \pm 1.10$ & $2.65+$ & $6.10 \pm 1.27$ & $6.32 \pm 1.1$ & $3.60+$ & $5.55 \pm 1.09$ & $6.35 \pm 1.24$ & $14.41+$ \\
\hline PIF (1t/s) & $2.89 \pm 1.42$ & $2.70 \pm 1.38$ & $6.57-$ & $1.98 \pm 0.82$ & $2.25 \pm 0.88$ & $13.63+$ & $2.55 \pm 1.37$ & $2.72 \pm 1.41$ & $6.66+$ \\
\hline $\operatorname{EVC}(1 t)$ & $2.90 \pm 0.51$ & $2.92 \pm 0.44$ & $0.68+$ & $2.97 \pm 0.62$ & $3.07 \pm 0.57$ & $3.36+$ & $2.94 \pm 0.62$ & $3.12 \pm 0.50$ & $6.04+$ \\
\hline $\operatorname{MVV}(1 \mathrm{t} / \mathrm{min})$ & $99.21 \pm 12.7$ & $102.6 \pm 13.8$ & $3.45+$ & $103.3 \pm 16.1$ & $115.2 \pm 16.6$ & $11.58+$ & $103.2 \pm 17.1$ & $117.4 \pm 15.5^{* *}$ & $13.77+$ \\
\hline
\end{tabular}

$(* * \mathrm{p}<0.01)$

(FEV1: Forced expiratory volume in 1 second, FEV1/FVC: Forced expiratory volume in 1 second/forced vital capacity ratio, PEF: Peak expiratory flow, PIF: Peak inspiratory flow, EVC: Expiratory vital capacity)

Table 4. Gas Analysis of Obese Women $(n=63)$

\begin{tabular}{|c|c|c|c|c|c|c|c|c|c|}
\hline \multirow[t]{2}{*}{$\begin{array}{c}\text { Groups } \\
\mathrm{n}\end{array}$} & \multicolumn{3}{|c|}{$\begin{array}{c}\text { Control }(\mathrm{C}) \\
22\end{array}$} & \multicolumn{3}{|c|}{$\begin{array}{c}\text { Aerobic }(\mathrm{A}) \\
21\end{array}$} & \multicolumn{3}{|c|}{$\begin{array}{c}\text { Aerobic-Strength (AS) } \\
20\end{array}$} \\
\hline & Before & After & $\begin{array}{c}\% \\
\text { change }\end{array}$ & Before & After & $\begin{array}{c}\% \\
\text { change }\end{array}$ & Before & After & $\begin{array}{c}\% \\
\text { change }\end{array}$ \\
\hline $\mathrm{VO}_{2}(1$ & $10.5 \pm 25$ & $1975.7 \pm 236$ & 1.74 & $1984 \pm 264$ & $1995.3 \pm 217$ & 0.5 & $2219=$ & 2176 & $3.27-$ \\
\hline $\mathrm{VCO}_{2}(\mathrm{ml} / \mathrm{SF})$ & $2193.7 \pm 30$ & $2104.6 \pm 303$ & $4.05-$ & $2196 \pm 334$ & $2129.9 \pm 263$ & 3.0 & 2396 & 226 & $5.57-$ \\
\hline $\mathrm{VE} / \mathrm{VO}_{2}(\mathrm{ml})$ & $33.86 \pm 3.35$ & $32.54 \pm 3.50$ & $3.89-$ & $35.14 \pm 4.60$ & $34.09 \pm 4.51$ & $2.98-$ & $33.9 \pm 4.7$ & 34.00 & $0.26+$ \\
\hline $\mathrm{VE} / \mathrm{VCO}_{2}(\mathrm{ml})$ & $30.36 \pm 3.09$ & $29.56 \pm 2.69$ & $2.63-$ & $30.66 \pm 1.95$ & $31.80 \pm 2.74$ & $3.71+$ & $29.85 \pm 3.18$ & $31.45 \pm 3.67 * *$ & $* * 5.41+$ \\
\hline $\mathrm{VO}_{2} \max (\mathrm{ml} / \mathrm{kg} / \mathrm{min})$ & $25.24 \pm 3.50$ & $25.01 \pm 3.13$ & $0.20-$ & $24.41 \pm 3.88$ & $26.48 \pm 2.99^{*}$ & * $8.48+$ & $25.53 \pm 3.25$ & $26.91 \pm 3.94$ & $6.15+$ \\
\hline Max. HR (bpm) & $169.8 \pm 11.5$ & $165.9 \pm 11.2$ & $2.36-$ & $170.7 \pm 13.2$ & $169.71 \pm 11.8$ & $0.61-$ & $172.2 \pm 11.9$ & $169.3 \pm 12.9$ & 1.69 \\
\hline Max. Exercise time (min) & $10.52 \pm 1.47$ & $10.74 \pm 1.24$ & $2.09+$ & $10.15 \pm 1.07$ & $12.56 \pm 1.36^{*}$ & * 23.74+ & $10.57 \pm 1.14$ & $12.42 \pm 0.83$ & $18.65+$ \\
\hline
\end{tabular}

$\left({ }^{*} \mathrm{p}<0.04\right.$ compared to the Control, $* * \mathrm{p}<0.01$ compared to the Control)

(VE/ $\mathrm{VO}_{2}:$ Ventilation/oxygen consumption ratio, $\mathrm{VE} / \mathrm{VCO}_{2}:$ Ventilation/carbon dioxide production ratio, Max.HR: Maximum heart rate).

anthropometric parameters in the A group. In the $\mathrm{C}$ group, no significant changes in anthropometric values were found after 8 weeks.

As shown in Table 3, there were increases in all of the spirometry parameters in both the A and AS groups, but only FVC and MVV in the AS group showed significant increases (16.19\% and 13.77\%) according to one-way ANOVA.

The mean, SD, percentage change and one-way ANOVA results of gas analysis measurement of the obese women are presented in Table 4. After $8 \mathrm{wk}$ of training the study groups (A and AS) demonstrated $8.48 \%$ and $6.15 \%$ increases in $\mathrm{VO}_{2}$ max. According to one-way ANOVA, this increase was significant in the A group. There were no significant changes in gas analysis parameters in C group.

\section{DISCUSSION}

In this study, we investigated the effects of aerobic exercise and upper body muscle strength training on cardiopulmonary function of obese women. Our data show that anthropometric parameters, except for the $\mathrm{W} / \mathrm{H}$ ratio, significantly decreased in the A and AS groups compared to the C group. From these results, we can say the diet and exercise programme positively changed the morphological structure of the obese women.

In 1988, Ballor et al. assessed the effects weight training on body composition in an 8 week weight loss study of obese women. They found that resistance training resulted in increased strength and gains in muscle size during weight loss ${ }^{14}$.

It is well know that obesity affects 
cardiorespiratory functions. Most pulmonary dysfunction studies of obese individuals have shown the presence of restrictive patterns, with reduction of pulmonary volumes and capacities ${ }^{15}$. Some previous studies reported that FVC, FEV1, ERV, FRC, MVV and FEF25-75 parameters significantly decreased in morbidly obese patients $^{16-18)}$.

In the present study, we determined that the pulmonary function test results of the obese women were close to reference values. This result may be related to the fact that the number of morbidly obese subjects was less than moderately and mildly obese women in this study $(25.3 \%$ morbidly obese, $46 \%$ moderately obese and $28 \%$ mildly obese women).

Many researchers have shown increased pulmonary function with weight loss without exercise, because there are restrictive effects of excessive fat mass surrounding the abdomen and chest $^{19}$ ). While aerobic training may be more effective at increasing peak oxygen consumption ${ }^{20}$, strength training may also strengthen the muscles of the rib cage, abdominal wall, and upper extremities and may be of particular benefit in pulmonary rehabilitation due to enhancement of inspiration ${ }^{10)}$.

In this study, we found an increase in all of the pulmonary function parameters in the A and AS groups after 8 weeks. When we compared pre- and post-intervention measurements of the 3 groups with one-way ANOVA, the findings showed that there were statistically significant differences in FVC and MVV of the AS group. We consider that there was a positive effect especially in pulmonary function due to the effect of strength training of upper body muscles, whereas there was no change in gas analysis and only a little effect on anthropometric measurements. Cotes (1979) reported that the strength of accessory respiratory muscles could be increased with strength training of shoulder girdle muscles, leading to an increase in vital capacity ${ }^{8)}$. Also, Eston reported that MVV can be increased by strength training of respiratory muscles $^{11)}$. Besides, O'Donnell et al. found that general exercise training, when targeted at high levels of ventilation, significantly increased the strength and endurance of ventilatory muscles in severe chronic obstructive pulmonary disease ${ }^{21)}$. Depalo at al. (2004) reported that performing biceps curls and sit-up maneuvers 4 times weekly for $8 \mathrm{wk}$ not only strengthened the muscles of the rib cage but also provided sufficient strength training.

Previous studies have shown that obese persons have decreased performance and therefore they may tire earlier than normal persons. $\mathrm{VO}_{2}$ and $\mathrm{VCO}_{2}$ of obese subjects are higher than normal subjects at rest and during exercise, and minute ventilation (VE) increases at a relatively faster rate during exercise, producing a significantly greater ventilation equivalent for oxygen consumption $\left(\mathrm{VE} / \mathrm{VO}_{2}\right)$ in obese subjects ${ }^{22}$.

In this study, $\mathrm{VO}_{2}$ max values of the A group and the AS group were increased $8.48 \%$ and $6.15 \%$, respectively. In the comparison of the 3 groups by one-way ANOVA, the findings showed that there was a statistically significant difference between the pre-and post-intervention $\mathrm{VO}_{2}$ max values of the $\mathrm{A}$ group $(\mathrm{p}<0.01)$. This result indicates that diet plus aerobic exercise efficiently improved endurance but additional strength training did not affect the result. However, increased accessory muscles endurance with strength training can increase general endurance indirectly. Because early fatigue of respiratory muscles may cause hyperventilation the anaerobic threshold occurs early thereby limiting performance. Thus, VE is decreased by training of respiratory muscles and the anaerobic threshold time will be extended.

Previous studies have shown that strength training alone does not increase $\mathrm{VO}_{2} \max$ but increases exercise time. It was shown that, in a running training period of 20 weeks, endurance of respiratory muscles increased $16 \%$ ratio in a healthy person ${ }^{23)}$. Diaz Cisneros et al. found that $\mathrm{O}_{2}$ uptake increased $11.3 \%$ after diet and moderate aerobic exercise of 12 weeks $^{24)}$. Also, Keim et al. ${ }^{25)}$ found similar results for obese women.

The present study showed that aerobic exercise is required for improvement of aerobic capacity. In this study, while $\mathrm{O}_{2}$ uptake was increased by diet plus aerobic exercise or aerobic exercise alone, $\mathrm{O}_{2}$ uptake wasn't significantly increased by strength training alone, because it was not enough to induce weight loss.

In conclusion, it is known that obese women have decreased pulmonary function and oxygen uptake because of weak respiratory muscles and they tire quicker than non-obese women. Diet and aerobic training undertaken by obese women significantly improved their morphological structure and their aerobic capacity. However, diet plus aerobic and strength training significantly increased the muscle 
strength of upper body and accessory respiratory muscles. Therefore this positive improvement may have resulted in reduced pulmonary diffuculty because more air was inspired and expired $b$ the lungs due to increased pulmonary function.

\section{REFERENCES}

1) Heyward VH: Advanced Fitness Assessment \& Exercise Prescription. 2 ed. Illinois: Human Kinetics Books, 1991.

2) Thalmann S, Meier CA: Local adipose tissue depots as cardiovascular risk factors. Cardiovasc Res, 2007, 75: 690-701.

3) McArdle WD, Katch FI, Katch VL: Essentials of Exercise Physiology. 2 ed. London: Lippincott Williams \& Wilkins, 2000.

4) Sahebjami H: Dispne in obese healty men. Chest, 1998, 114: 1373-1377.

5) Canoy D, Luben R, Welch A, et al.: Abdominal obesity and respiratory function in men and women in the EPIC-Norfolk study, United Kingdom. Am J Epidemiol, 2004, 159: 1140-1149.

6) Sahebjami H, Gartside PS: Pulmonary function in obese subjects with a normal FEV1/FVC ratio. Chest, 1996, 110 (6): 1425-1429.

7) Zavorsky GS, Murias JM, Kim DJ, et al.: Waist-to-hip ratio is associated with pulmonary gas exchange in the morbidly obese. Chest, 2007, 131: 362-367.

8) Ries AL, Carlin BW, Kohlman VC, et al.: Pulmonary rehabilitation. Chest, 1997, 112: 1363-69.

9) Al-bilbeisi F, Mccool FD: Diaphragm recruitment during nonrespiratory activities. Am J Respir Crit Care Med, 2000, 162: 456-459.

10) DePalo VA, Parker AL, Al-Bilbeisi F, et al.: Respiratory muscle strength training with nonrespiratory maneuvers. J Appl Physiol, 2004, 96: 731-734.

11) Eston R, Reilly $T$ : Kinanthropometry and Exercise Physiology Laboratory Manual. London: E\&FN Spon, 1996.

12) Pollock ML, Garzarella L, Graves JE: The Measurement of Body Composition. In: Maud PJ, Foster C (eds.), Physiological Assessment of Human Fitness. Champaign: Human Kinetics, 1995.
13) Pearl B, Moran GT: Getting Stronger. Canada: Shelter Pub, 1986.

14) Ballor DL, Katch VL, Becque MD, et al.: Resistance weight training during caloric restriction enhances lean body weight maintenance. Am J Clin Nutr, 1988, 47(1): 19-25.

15) Magnani KL, Cataneo AJM: Respiratory muscle strength in obese individuals and influence of upperbody fat distribution. Sao Paulo Med J, 2007, 125(4):215-9.

16) Babb TG, Buskirk ER, Hodgson J: Exercise endexpiratory lung volumes in lean and moderately obese women. Int J Obes, 1989, 13(1): 11-19.

17) Ferretti A, Giampiccolo P, Cavalli A, et al.: Expiratory flow limitation and orthopnea in massively obese subjects. Chest, 2001, 119: 1401-1408.

18) Biring MS, Lewis MI, Liu JT, et al.: Pulmonary physiologic changes of morbid obesity. Am J Med Sci, 1999, 318:5, 293-297.

19) Sanya AO, Adesina AT: Relationship between estimated body fat and some respiratory function indices. Cent Afr J Med, 1998, 44(1): 254-258.

20) Geliebter A, Maher MM, Gerace L, et al.: Effects of strength or aerobic training on body composition, resting metabolic rate, and peak oxygen consumption in obese dieting subjects. Am J Clin Nutr, 1997, 66: 557-563.

21) O'Donnell DE, Mcguire M, Samis L, et al.: General exercise training improves ventilatory and peripheral muscle strength and endurance in chronic airflow limitation. Am J Respir Crit Care Med, 1998, 157: 1489-1497.

22) Luce JM: Respiratory complications of obesity. Chest, 1980, 78: 626-631.

23) Luttgens K, Wells KF: Kinesiology. 7 ed. Iowa: Brown Pub, 1989.

24) Diaz Cisneros FJ, Rivera Cisneros AE, Lopez Martinez MG, et al.: Effects of an aerobic exercise program and diet on body composition and cardiovascular function in obese persons. Arch Inst Cardiol Mex, 1986, 56(6): 527-533.

25) Keim NL, Barbieri TF, Van Loan MD, et al.: Energy expenditure and physical performance in overweight women: response to training with and without caloric restriction. Metabolism, 1990, 39(6): 651-658. 